\title{
ASSESSMENT OF EXISTING STEEL FRAMES WITH INFILLS UNDER MULTIPLE EARTHQUAKES
}

\section{Luigi Di Sarno ${ }^{1}$, Jing-Ren Wu ${ }^{1}$, Mario D'Aniello ${ }^{2}$, Silvia Costanzo ${ }^{2}$, Raffaele Landolfo ${ }^{2}$, Oh-Sung Kwon ${ }^{3}$, Fabio Freddi ${ }^{4}$}

\author{
${ }^{1}$ Dept. of Civil Engineering and Industrial Design, University of Liverpool \\ The Quadrangle, Brownlow Hill, Liverpool, United Kingdom \\ \{luigi.di-sarno, jingren.wu\}@liverpool.ac.uk \\ ${ }^{2}$ Dept. of Structures for Engineering and Architecture, University of Naples Federico II \\ Corso Umberto I 40, Naples, Italy \\ \{mdaniel, silvia.costanzo, landolfo\}@ unina.it \\ ${ }^{3}$ Dept. of Civil and Mineral Engineering, University of Toronto \\ 35 St. George Street, Toronto, Canada \\ os.kwon@utoronto.ca \\ ${ }^{4}$ Dept. of Civil, Environment and Geomatic Engineering, University College London \\ Gower Street, London, United Kingdom \\ f.freddi@ucl.ac.uk
}

\begin{abstract}
Many existing steel multi-storey frames in Europe were designed prior to the provisions of modern seismic design codes; therefore, they often exhibit low resistance to earthquakes due to their insufficient energy dissipation capacity. However, the current framework for assessing existing structures in EC8-3 is inadequate and should be reviewed. Particular attention should be paid to the contribution from masonry infill walls as they significantly affect the modal properties and the lateral stiffness of structures. To this end, two $3 D$ models of a two-storey steel moment-resisting frame were developed to assess the applicability of the current framework in EC8-3 to the infilled structures under multiple earthquakes through nonlinear analyses. The modelling of masonry infill walls was achieved through a macro-model using equivalent diagonal struts. The ground motions utilised during the analyses took the records of the recent 2016 Central Italy earthquake sequence. As part of the project HITFRAMES, this paper serves as a preparation for the experiment to be conducted in Greece.
\end{abstract}

Keywords: Existing steel frames, Assessment, Pseudo-dynamic testing, Seismic response, Modal calibration. 


\section{INTRODUCTION}

Nowadays, modern seismic design codes have recognised the importance of the inelastic behaviour of structures during earthquake and provided guidelines for designing ductile structures with sufficient capability of dissipating energy. However, numerous existing steel frames were designed prior to the provisions of model seismic design codes and were designed to gravity loading only. Those frames are often characterised by inadequate energy dissipation capacity due to their non-ductile connections and slender beams and columns [1], and therefore, high vulnerability to earthquakes. Global collapse and severe local damage have been observed in such frames in the aftermath of the 2016 Amatrice earthquake in Central Italy. Public attention has been attracted to the urgent need of a rigorous framework of assessing the seismic vulnerability of existing steel frames $[1,2]$.

Many code-based procedures for assessing and retrofitting existing steel frames has been developed so far, such as EC8-3 in Europe [3] and ASCE41-13 in the US [4]. Those codified assessment procedures generally adopt the concept of performance-based earthquake engineering and allow both linear and nonlinear analysis of frame models to be carried out, though with some restrictions on the linear methods. However, a recent review of the EC8-3 by Araújo and Castro [4] summarised some inconsistencies and limitations in the European code, for example, the different analysis methods provided in EC8-3 may cause significant inconsistencies in demand estimations and it seems that the predefined capacity criteria for different limit states in terms of member plastic rotations are a direct reproduction of the former version of American code ASCE41-06, which were based on tests of typical American cross section profiles rather than the European profiles [4]. Another important issue is that the current EC8-3 only defines the behaviour requirements of non-structural members in a qualitative manner, through the definition of each limit states. Besides, since the EC8-3 requires safety check of every individual member, the assessment process can be extremely time-consuming and the onset of failure of a limit state is simply decided by the first member that exceeds corresponding criteria, which tends to neglect the redundancy of a structure. Consequently, further revision of EC8-3 is necessary for the next generation of Eurocode 8 regarding both the analysis methods and compliance criteria.

As an important part of the assessment of existing steel frames, selection of the most appropriate numerical model is strongly dependent on the specific target that is set to achieve. A comprehensive model that contains more detailing than a bare frame may lead to higher reliability of structural performance estimation, but this is not always true because of the complex nature of the interactions among structural and non-structural components, such as the masonry infill walls, beam-to-column connections and composite slab. It is now widely accepted that the contribution of infill walls to the lateral stiffness and strength of steel frame is significant and should be taken into consideration in assessing existing steel frames $[1,5]$. Several previous studies have tried to develop simple but reliable models of masonry infill walls and incorporated them into bare frame models. A macro-model of masonry infill wall was proposed which uses a single equivalent strut in each diagonal direction with appropriate strut mechanical properties to capture the strut action caused by infill walls to the confining frames $[5,6,7,8,9]$. This macro-model has an advantage in terms of its combined efficiency and accuracy in the assessment of global response, despite some compromise has to be made to the local behaviour of infill walls. A valid constitution law also plays an essential role in the equivalent strut model due to the non-homogenous nature of the material [5].

The main aim of this study is to present the assessment of a case steel moment resisting frame (MRF) based on the procedure in EC8-3. Nonlinear static and dynamic analysis was performed to estimate the demand and capacity for each limit states. The steel frame was de- 
signed to sustain gravity loading only following the design code EC3. A 3D model was established in the Open System for Earthquake Engineering Simulation (OpenSees) analysis software [10]. Special attention was paid to the contribution of masonry infills to the overall performance of the frame. In addition, multiple earthquakes were applied to the frame model in the nonlinear dynamic analyses so that potential cumulative damage on the structure was investigated as well. Capacity was assessed based on the criteria proposed in EC8-3 in terms of member plastic rotation. Criteria based on inter-storey drift ratio (IDR), which accounts for the stability of structures, were also used to assess the reliability of plastic rotation criteria.

\section{ASSESSMENT FRAMEWORK IN EC8-3}

This paper is aimed to present the assessment procedure of a steel frame based on the nonlinear analyses in EC8-3, therefore, a brief description of the framework is presented. The focus of this study is nonlinear analysis; hence the procedure of linear analysis is not included here.

Three limit states are defined in EC8-3, namely the Damage Limitation (DL) limit state, the Significant Damage (SD) limit state and the Near Collapse (NC) limit state, compared to two in EC8-1 for general rules [11], which are the DL and ultimate limit state. By definition, as concluded in Table 1, the return periods for the DL, SD and NC limit state are 225, 475 and 2475 years respectively, corresponding to probabilities of exceedance of $20 \%, 10 \%$ and $2 \%$ in 50 years. It is interesting to notice that the ultimate limit state in EC8-1 is equivalent to the SD limit state in EC8-3 in terms of their return periods, while NC limit state is actually closer to the real collapse of structures, hence associated with a much longer return period. The explanation given is that $\mathrm{NC}$ limit state makes full use of the deformation capacity of structural elements, while SD limit state (ultimate limit state) leaves some residual lateral drift and stiffness and loading carrying capacity of vertical elements [2]. It is also worth noting that the DL limit state in EC8-1 has a shorter return period than that in EC8-3, so the former is more conservative than the latter. The above comparisons indicate that the three limit states for existing buildings are defined to prevent collapse of buildings rather than upgrading them to satisfy the design requirements for new buildings [4].

\begin{tabular}{c|ccc|cc}
\hline \multirow{4}{*}{} & \multicolumn{3}{|c|}{ EC8-3 } & \multicolumn{2}{c}{ EC8-1 } \\
\cline { 2 - 6 } & DL & SD & NC & DL & Ultimate \\
\hline \multirow{3}{*}{$\begin{array}{c}\text { Hazard } \\
\text { level }\end{array}$} & 225 years & 475 years & 2475 years & 95 years & 475 years \\
\cline { 2 - 6 } & $\begin{array}{c}\text { 20\% in } 50 \\
\text { years }\end{array}$ & $\begin{array}{c}10 \% \text { in } 50 \\
\text { years }\end{array}$ & $\begin{array}{c}2 \% \text { in } 50 \\
\text { years }\end{array}$ & $\begin{array}{c}10 \% \text { in } 10 \\
\text { years }\end{array}$ & $\begin{array}{c}10 \% \text { in } 50 \\
\text { years }\end{array}$ \\
\hline
\end{tabular}

Table 1: Performance requirements for different limit states in EC8-1 and EC8-3.

The EC8-3 also provides some guidance on the data collecting of existing buildings, where information of geometry, detailing and materials should be gathered. Three knowledge levels are summarised to deal with the uncertainties during the process of surveying, from limited to full knowledge level. A confidence factor is assigned to each knowledge level, which is used in the assessment of capacity as a partial safety factor. For the purpose of this study, full knowledge is assumed, thus a confidence factor of 1.0 is taken and no reduction is required in the safety verification.

Safety check in terms of demand and capacity is the last stage in the assessment framework of EC8-3. In the context of nonlinear analysis, demand can be taken as the results of analysis 
directly, but capacity differs between ductile and brittle structural elements. For ductile elements, their deformation capacity will be compared with the deformation demand, while for brittle elements, internal force capacity shall be compared with the corresponding force demand. In the case of steel frames, which is the case of this study, EC8-3 requires safety check to be done considering the plastic rotation of columns and beams, where the capacity for each limit state is dependent on the yield rotation of each element, as summarised in Table 2 . The table applies to Class 1 and 2 cross-sections only and the dimensionless axial force $v$ should not exceed 0.3. EC8-3 does not give any limits on other cross-sections or with higher value of $v$. Recall that the criteria in Table 2 is in fact the same as the one used to be adopted in the American code ASCE41 for dimensionless axial force $v$ less than 0.2. For the determination of demand, i.e. the target displacement, in nonlinear static analysis, N2 method [12] is recommended by EC8-3.

\begin{tabular}{cccc}
\hline Class of cross-section & DL & SD & NC \\
\hline 1 & $1.0 \theta_{\mathrm{y}}$ & $6.0 \theta_{\mathrm{y}}$ & $8.0 \theta_{\mathrm{y}}$ \\
2 & $0.25 \theta_{\mathrm{y}}$ & $2.0 \theta_{\mathrm{y}}$ & $3.0 \theta_{\mathrm{y}}$ \\
\hline
\end{tabular}

Table 2: Plastic rotation capacity proposed in EC8-3 with dimensionless axial force $v \leq 0.3$.

For non-structural elements, requirements are described in the definition of three limit states qualitatively. For DL limit state, infill walls may experience some cracking, but damage shall be repaired at a low cost. For SD limit state, although infill walls are damaged, but outof-plane failure shall not happen. Finally, the NC limit state allows infill walls to be significantly damaged or even collapse. Quantitative specifications are not included in the current version of EC8-3.

\section{CASE STUDY AND NUMERICAL MODELLING}

The building considered in this study is a two-storey steel MRF, which has a rectangular layout in plan. The frame is 13.5 metres long, consisting of three bays, 8.5 meters in width and 6.6 metres in height with a storey height of 3.3 metres. Figure 1 shows the plan and side view of the frame. Composite floor slab and masonry infill walls are omitted for clarity. The steel frame was designed to resist gravity load only and does not have sufficient lateral stiffness and strength to survive a strong earthquake. The steel grade for all beams and columns is S355. The primary and perimeter beams are designed to be IPE270, all other beams are IPE200 and columns are HE240A. Moreover, beam-to-column connections are full penetration weld connection and the infill walls consist of two layers of $80-\mathrm{mm}$ thick perforated bricks with a compressive strength of $9.7 \mathrm{~N} / \mathrm{mm}^{2}$ bound together through M5 mortar. Regarding the loading conditions, the self-weight of slab was taken as $240 \mathrm{~kg} / \mathrm{m}^{2}$, the density of bricks is $855 \mathrm{~kg} / \mathrm{m}^{3}$ and a live load of $2 \mathrm{kN} / \mathrm{m}^{2}$ is also accounted for in the design.

\begin{tabular}{cccc}
\hline & Cracking & Ultimate & Residual \\
\hline Axial force $(\mathrm{kN})$ & 183 & 239 & 24 \\
Strain & 0.00009 & 0.00034 & 0.01063 \\
\hline
\end{tabular}

Table 3: Modelling parameters of the trilinear curve for masonry infill walls. 

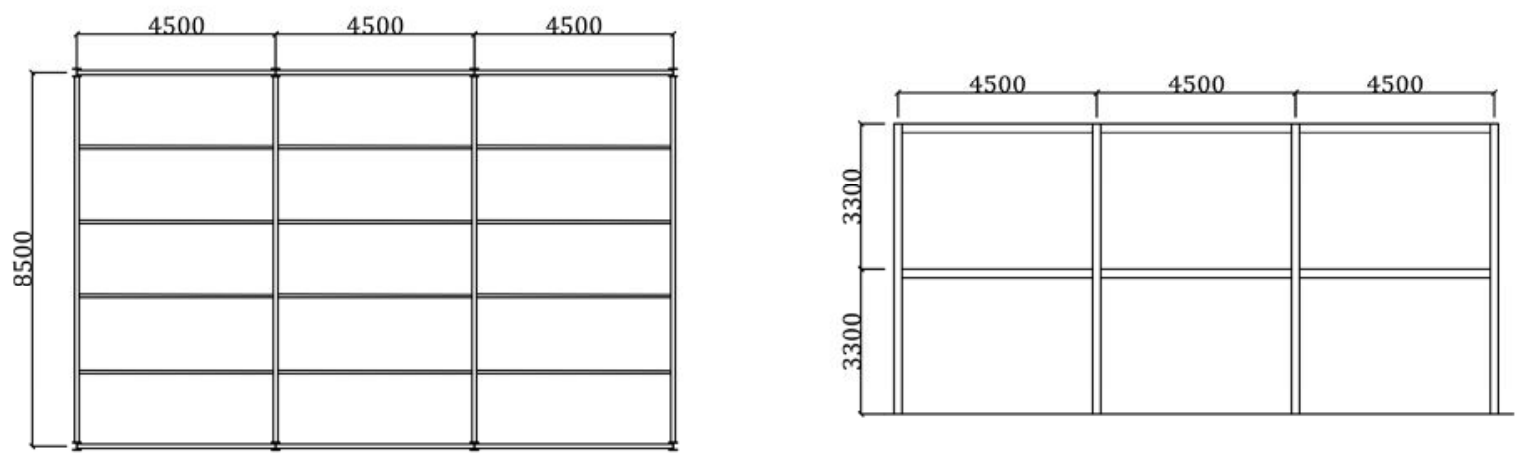

Figure 1: Plan layout and side view of the steel MRF.

Two 3D models of this steel MRF were established in OpenSees [10], namely a bare frame and an infilled frame. Columns were modelled using force-based beam-column elements with fibre section and 10 integration points along the length using Gauss-Lobatto integration method. Besides, the Steel01 material, which is a bilinear elastoplastic material model, was considered for structural steel with a hardening ratio of 0.02 . Plastic hinges in beams were assumed to form at the ends of members, through lumped plasticity zero-length elements. The zerolength elements possess a trilinear moment-rotation relationship based on the IbarraKrawinkler-Deterioration (IKD) model $[13,14]$ to represent the rotational behaviour of beams. The parameters if the IKD model were calibrated based on finite element analyses carried out in ABAQUS 6.14. Rigid diaphragm action was achieved using rigid diagonal struts. Regarding the infills, the equivalent strut model [5] was chosen due to its simplicity and accuracy for evaluating global response. The constitution law was based on the Fardis-Panagiotakos model, which is a trilinear curve accounting for the cracking and ultimate strength of masonry infills, as well as degrading after the ultimate strength is reached [6]. The model applies to compression only and zero tension is considered. Since the modelling of infill walls is a key point in this study, the modelling parameters are summarised in Table 3 . The analyses were performed in the longitudinal direction of the frame, as shown in Figure 1, where the weak axis of columns was involved and the contribution of infills were more significant.

\section{ASSESSMENT RESULTS}

\subsection{Modal analysis}

A modal analysis was performed at the beginning to capture the basic modal properties of the frame and the results are summarised in Table 4 . The information obtained here will be helpful in the following assessment of the steel frame.

\begin{tabular}{|c|c|c|c|}
\hline & & 1st mode & 2nd mode \\
\hline Perioc & $(\mathrm{sec})$ & 0.74 & 0.25 \\
\hline Modal n & iss $(\%)$ & $92 \%$ & $8 \%$ \\
\hline \multirow{2}{*}{ Mode shape } & 1st floor & 0.42 & 1.00 \\
\hline & 2nd floor & 1.00 & -0.54 \\
\hline
\end{tabular}

Table 4: Modal property of the bare frame in the longitudinal direction. 
It is anticipated from Table 4 that the seismic behaviour of the frame will be dominated by the fundamental mode, with a modal mass that accounts for $92 \%$ of the total mass. The modal analysis was performed on the bare frame only. The presence of infills increases the initial lateral stiffness by a considerable amount, hence the initial fundamental period of the infilled frame is much lower than that of the bare frame, which is around $0.05 \mathrm{sec}$. However, since the masonry infills crack and fail quickly during the analysis, a quick drop was observed in the lateral stiffness of the infilled frame, hence the fundamental period was very unstable. It was also expected that the infilled frame would eventually have similar fundamental period to the bare frame after the loss of all infill walls.

\subsection{Nonlinear static analysis}

A total of four pushover analyses were carried out in this study. EC8-3 requires at least two lateral load patterns should be used in pushover analysis, namely a uniform pattern and a modal pattern. The uniform pattern (denoted as U) consists of lateral loads proportional to the lumped mass of each node, while the modal pattern (denoted as $\mathrm{M}$ ) includes lateral loads proportional to both the mass and first mode shape of each node. Both of the two load patterns were applied to the bare and infilled frame. The performance points (demand) were determined based on the N2 method [12] suggested in EC8-1. The response spectrum adopts the Type 1 elastic response spectrum in EC8-1 for ground type B, and the reference peak ground acceleration was taken as $0.1975,0.25$ and $0.4275 \mathrm{~g}$ for DL, SD and NC limit state, respectively. The choice of these parameters was based on the seismicity in Central Italy, where severe earthquake events have occurred in the past few years, causing collapse of numerous steel MRFs. Figure 2 shows the response spectrum in acceleration-displacement (AD) form for each limit state, as well as the capacity curves for the original frames and the equivalent SDOF systems. Since the uniform and modal lateral load patterns provided very similar capacity curves, only the seismic demands obtained from the modal pattern are presented in this paper. The global and inter-storey drift ratios at each performance point are also presented in Table 5.

It is clearly shown in Figure 2 that the presence of infill walls significantly increased the initial stiffness and maximum base shear of the frame. Besides, based on a damage assessment, it is found that columns in both models yield prior to the beams, which remain in elastic range up to NC limit state. This weak column-strong beam (WCSB) scenario is undesirable in modern seismic design code, which tends to concentrate plastic deformation within certain floors and increase seismic demands $[15,16]$. It is also observed that for the bare frame, no plastic hinges were formed in columns at the DL and SD limit state. However, at NC limit state, plastic hinges were found in all ground floor columns of the bare frame, indicating that the frame was about to lose its load carrying capacity in the vertical direction. On the other hand, for the infilled frame, plastic hinges began to form at the point of maximum base shear, right after the exhaustion of ground floor infill walls. The turning point at $1.15 \%$ global drift marks the formation of plastic hinges in all ground floor columns. Apparently, the columns in the infilled frame failed quickly than those in the bare frame. This is possibly due to the strut action of the infill walls which caused higher local force on columns. In addition, as a result of the WCSB characteristic, all infills on the ground floor collapsed at the point of maximum base shear while those on the first floor barely cracked. Therefore, the presence of infills had great effects on the seismic behaviour of steel MRFs, emphasising the necessity of including infill walls in the seismic assessment. 

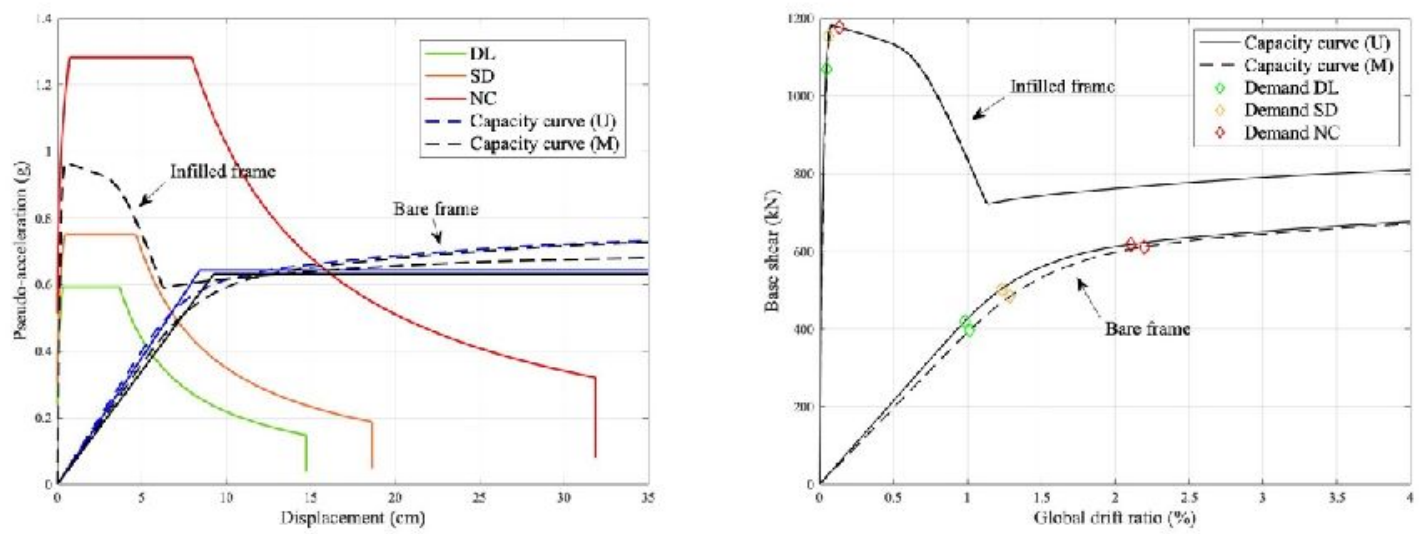

Figure 2: Response spectrum in $\mathrm{AD}$ form and capacity curves of the original frames (right) and the equivalent SDOF systems (left).

\begin{tabular}{cccccccc}
\hline & & \multicolumn{3}{c}{ Bare } & \multicolumn{3}{c}{ Infilled } \\
\cline { 3 - 8 } & & DL & SD & NC & DL & SD & NC \\
\hline \multirow{2}{*}{ Global } & Uniform & 0.99 & 1.23 & 2.11 & \multirow{2}{*}{0.04} & \multirow{2}{*}{0.06} & \multirow{2}{*}{0.14} \\
& Modal & 1.02 & 1.29 & 2.20 & & & \multirow{2}{*}{0.26} \\
\hline \multirow{2}{*}{ Ground } & Uniform & 1.13 & 1.45 & 2.88 & \multirow{2}{*}{0.08} & \multirow{2}{*}{0.09} & \multirow{2}{*}{ floor } \\
\multirow{2}{*}{ 1st floor } & Modal & 1.09 & 1.40 & 2.78 & & & \multirow{2}{*}{0.01} \\
& Uniform & 0.81 & 0.98 & 1.27 & \multirow{2}{*}{0.02} & 0.02 & \\
\hline
\end{tabular}

Table 5: Global and inter-storey drift ratios (\%) obtained from nonlinear static analyses.

An important step of the N2 method in EC8 is that an idealised bilinear curve should be derived to represent the behaviour of the equivalent SDOF system, as presented in Figure 2. However, a bilinear idealisation seems not appropriate in the case of infilled frames based on the shape of its capacity curve. As a result, the initial stiffness was adopted to continue the N2 method. Apparently, from Figure 2 and Table 5, the seismic demands on the infilled frame is much lower than those on the bare frame, because the presence of infill walls resulted in a sharp increase in the lateral stiffness and strength. However, the $\mathrm{N} 2$ may yield nonconservative estimation at the short-period range due to the high sensitivity of inelastic displacement to the change of structures [12]. In this study, the infill walls cracked and failed shortly after the start of pushover analysis, caused the global lateral stiffness to quickly decrease and eventually to be the same as that of the bare frame. Therefore, further research should be carried out to find out a more accurate rule for structures in the short-period range, where the effects due to changes of structural parameters are accounted for.

\subsection{Nonlinear dynamic analysis}

The time-history analysis utilised the records for the earthquake sequence initiated in Amatrice, a town in Central Italy, on 24th of August 2016. The Amatrice earthquake sequence includes one mainshock and four aftershocks whose peak ground accelerations are larger than $1.0 \mathrm{~g}$. The basic information of those strong ground motions is provided in Table 6 , and the accelerogram and pseudo-acceleration spectrum for 5\% damping are shown in Figure 3. EC83 requires at least 7 earthquake records to be involved in the time-history analysis, however, 
the focus in this analysis is to investigate the potential effects of earthquake sequence and the presence of infill walls. Therefore, only one earthquake sequence is considered in this study.

As shown in the spectrum in Figure 3, the spectral acceleration of the unscaled record of mainshock at the fundamental period is $0.365 \mathrm{~g}$, which is less than the spectral acceleration at fundamental period corresponding to the DL limit state. This indicates that the frame may still be within the elastic range under the unscaled records. In order to observe some damage on the frame, the entire earthquake sequence was scaled by a factor of 1.37 and 2.36 such that the spectral acceleration of the new earthquake records at fundamental period equal to the one corresponding to the SD and NC limit state, thus the two scaled earthquakes are denoted as $\mathrm{SD}$ and NC, respectively. The spectral acceleration at fundamental period was used as the scaling parameter because as mentioned in the modal analysis, the seismic response of the steel frame in this study is dominated by the first mode, which takes up more than $90 \%$ of total mass. The mainshock record was applied to the frame alone at first and then with its aftershocks to represent single and multiple earthquakes.

\begin{tabular}{cccccccc}
\hline Event & Date & $\mathrm{M}_{\mathrm{w}}$ & $\mathrm{M}_{\mathrm{L}}$ & $\mathrm{R}_{\text {epi }}(\mathrm{km})$ & PGA $(\mathrm{g})$ & PGV (cm/s) & PGD (cm) \\
\hline $\mathrm{M} / \mathrm{S}$ & 24-Aug-2016 & 6.0 & 6.0 & 8.5 & 0.87 & 43.5 & 8.5 \\
$\mathrm{~A} / \mathrm{S} 1$ & 24-Aug-2016 & 4.3 & 4.5 & 3.6 & 0.19 & 6.8 & 0.5 \\
$\mathrm{~A} / \mathrm{S} 2$ & 24-Aug-2016 & 5.3 & 5.4 & 20.9 & 0.11 & 5.1 & 0.9 \\
$\mathrm{~A} / \mathrm{S} 3$ & 25-Aug-2016 & 4.4 & 4.3 & 3.6 & 0.23 & 9.6 & 0.6 \\
$\mathrm{~A} / \mathrm{S} 4$ & 26-Aug-2016 & 4.8 & 4.7 & 3.1 & 0.34 & 11.0 & 0.6 \\
\hline
\end{tabular}

Table 6: Summary of the Amatrice earthquake sequence.
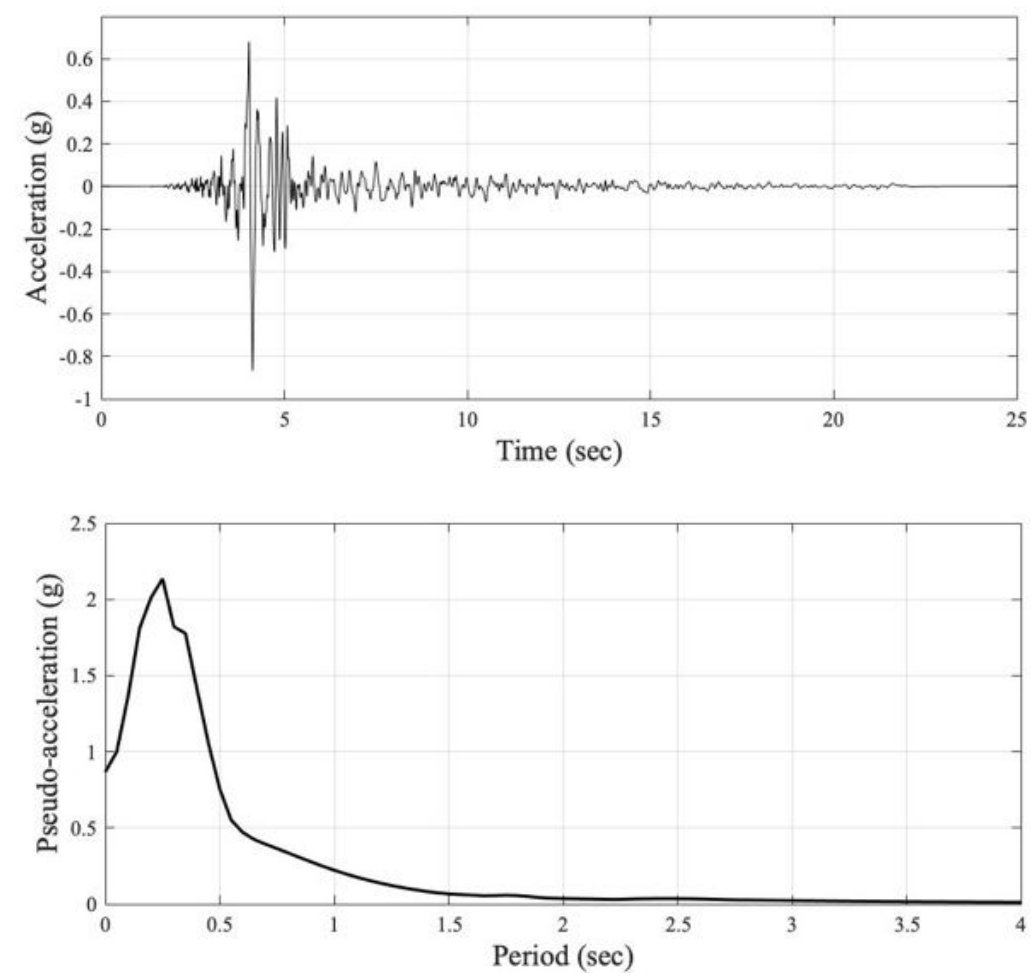

Figure 3: Accelerogram and pseudo-acceleration spectrum for 5\% damping of the mainshock. 


\begin{tabular}{cccccc}
\hline & & \multicolumn{3}{c}{ Bare } & Infilled \\
\cline { 3 - 6 } & & SD & NC & SD & NC \\
\hline \multirow{2}{*}{ Global } & single & 1.26 & 2.18 & 0.26 & 1.34 \\
& multiple & 1.26 & 2.18 & 0.26 & 1.34 \\
\hline \multirow{2}{*}{ Ground } & single & 1.46 & 2.73 & 0.50 & 2.67 \\
floor & multiple & 1.46 & 2.73 & 0.50 & 2.67 \\
\multirow{2}{*}{ 1st floor } & single & 1.37 & 1.87 & 0.03 & 0.04 \\
& multiple & 1.37 & 1.87 & 0.03 & 0.04 \\
\hline Residual & single & 0.05 & 0.44 & 0.02 & 0.60 \\
drift & multiple & 0.05 & 0.44 & 0.02 & 0.60 \\
\hline
\end{tabular}

Table 7: Peak global and inter-storey drift ratio and residual drift ratio (\%) obtained from nonlinear dynamic analyses.

The failure mechanisms in time-history analysis under single or multiple earthquakes are similar to those in the pushover analysis. The occurrence of column plastic hinges and infill failure is limited to the ground floor, while beams are too strong to enter plastic range. Besides, the presence of infill walls led to higher local force at beam-to-column connections and accelerated the yield of columns.

The peak global, inter-storey and residual drift ratios of the bare and infilled frame obtained under single and multiple earthquakes are presented in Table 7. It is observed that there is no difference between the peak and residual drift ratios under single and multiple earthquakes. This is primarily due to the WCSB characteristic of the frame which led to the failure of columns but kept beams safe. Also, as a matter of numerical modelling, deterioration in unloading and reloading was not considered in the columns, and the aftershocks were not strong enough to activate columns into plastic range again. This is a major limitation of this study and further study addressing this issue should be conducted in the future. It is also noticed in Table 7 that the ground floor drift ratio of the infilled frame was nearly twice the global drift ratio, indicating that the global drift was in fact equal to the ground floor drift. This behaviour is significantly different from that of the bare frame, possibly due to the quick failure of ground floor infill walls and columns, causing the lateral stiffness of ground floor to be much lower than the first floor. When comparing with the results from nonlinear static analyses, good consistency was found for the bare frame. However, for the infilled frame, nonlinear static analysis gives extremely underestimated prediction of seismic demands, although it captured the same behaviour of lateral drift as nonlinear dynamic analysis did.

\subsection{Safety verifications}

At the safety verification stage, the seismic demands obtained from the nonlinear analyses are compared with the capacity determined based on the compliance criteria in EC8-3, which are based on the rotation of beams and columns. EC 8-3 also requires that no yielding or buckling shall occur in columns for DL and SD limit state. To calculate the yield rotation of columns, the following equation is adopted:

$$
\theta_{y}=\frac{M_{p l, R d} L_{s}}{3 E I}\left(1-\frac{N_{E d}}{N_{p l, R d}}\right) \#(1)
$$

This equation is not proposed in the EC8-3 and is sligitly different from the one proposed in the American code which uses half the length of element in the equation rather than the actual shear span $\mathrm{L}_{\mathrm{s}}$. Apart from the criteria proposed in EC8-3, previous studies also suggested the 
check of IDR to ensure the stability of structures $[2,17,18]$. The recommended criteria of IDR in [18] for SD and NC limit state is given in Table 9. The value for DL limit state was derived from the serviceability requirement in EC8-1. Recall that the DL limit state in EC8-1 is more conservative than the DL limit state defined in EC8-3, the value of $1 \%$ may also be slightly conservative.

The capacity curves from pushover analyses incorporated capacity points are presented in Figure 4. In Figure 4, R represents the capacity of element rotation while D represents the capacity of IDR. It is obvious that for both frames, the rotation criteria only give more conservative predictions at the DL limit state. This indicates that the performance level at SD and NC limit state are not guaranteed by only using the rotation criteria. Also, in the case of bare frame, the locations of capacity points well match the definition of each limit state in EC8-3. However, for the infilled frame, the capacity points tend to correspond to a worse situation than that defined in EC8-3. For the safety verification, the bare frame failed the DL limit state but fulfilled the requirement of SD and NC limit state.

\begin{tabular}{llll}
\hline & DL & SD & NC \\
\hline IDR $(\%)$ & 1.0 & 2.5 & 4.0 \\
\hline
\end{tabular}

Table 8: Criteria in terms of IDR for each limit state.

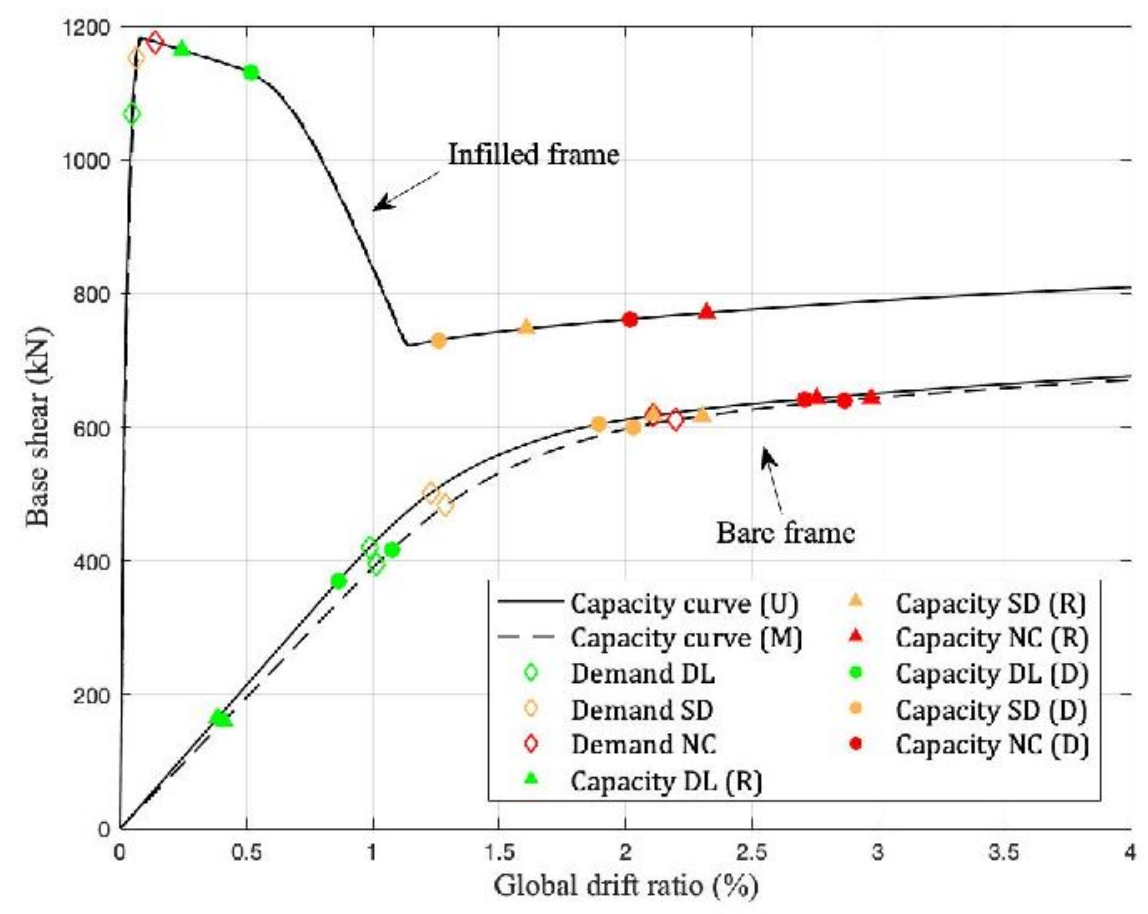

Figure 4: Capacity curves with demand and capacity points for safety verification.

The verification based on the results from nonlinear dynamic analyses was carried out by firstly checking each individual beam and column and then the IDR in Table 7. It is found that the bare and infilled frame survived the SD limit state under the SD earthquake, and survived the NC limit state only under the NC earthquake. Therefore, good consistency has been observed in the final verification results between the nonlinear static and dynamic analysis. 


\section{CONCLUSIONS}

This paper presents a brief assessment of a steel MRF based on the framework in EC8-3 using nonlinear static and dynamic analysis. The potential effects of the presence of masonry infill walls and the use of multiple earthquakes instead of a single earthquake are investigated. A modal analysis was performed at first, indicating that the seismic behaviour of the steel frame is dominated by its first mode, with a natural period of $0.74 \mathrm{sec}$. Nonlinear static and dynamic analyses were also performed and the following findings are concluded:

1. The presence of infill walls increases the initial lateral stiffness and strength significantly. An approximate $100 \%$ increase is found in the maximum base shear due to the incorporation of infill walls. The strut action induced by the infill walls causes the columns to fail earlier, which also affects the failure mechanism of the frame.

2. The sharp increase in the initial lateral stiffness puts the infilled frame in the shortperiod range, where the accuracy of $\mathrm{N} 2$ method is not guaranteed and non-conservative estimation may be provided. Big differences were found between the global and interstorey drift ratios for the infilled frame from pushover and time-history analyses, while good consistency was observed in the performance points obtained for bare frame.

3. The use of multiple earthquakes does not influence the assessment results in this case study. This is because of the WCSB nature of the frame structure, whose failure mechanism is controlled by columns, as well as the modelling of structural steel for columns, which does not consider any deterioration in unloading and reloading stiffness.

4. The use of criteria based on beam and column rotation proposed by EC8-3 is not enough in this study, which does not address the issue due to stability. A criterion based on IDR gives more conservative capacity points than the rotation criteria for this case frame under SD and NC limit state.

Further research should be carried out to address the applicability of N2 method in the short-period range, which accounts for the presence of essential non-structural elements like the infill walls. This limitation of the N2 method also restrict the applicability of the bilinear idealisation proposed in EC8-1, which is no longer suitable for the case of an infilled frame. Further research using refined models which take degrading and deterioration of columns into consideration should also be conducted to assess the cumulative damage in columns under multiple earthquakes.

\section{ACKNOWLEDGEMENT}

The financial support from Seismic Engineering Research Infrastructure for HITFRAMES (SERA) Project, funded within the H2020-INFRAIA-2016-2017 Framework Programme of the European Commission under grant agreement No.730900 is greatly appreciated. Any opinions, findings and conclusions, or recommendations expressed in this paper are those of the authors and do not necessarily reflect those of SERA sponsors.

\section{REFERENCES}

[1] L. Di Sarno, F. Paolacci, A.G. Sextos, Seismic performance assessment of existing steel buildings: a case study, InKey Engineering Materials, 763, 1067-1076. 
[2] M. Araújo, J.M. Castro, A critical review of European and American provisions for the seismic assessment of existing steel moment-resisting frame buildings. Journal of Earthquake Engineering, 22(8), 1336-1364, 2017.

[3] British Standards Institution, BS EN 1998-3:2005, Eurocode 8. Design of structures for earthquake resistance - Part 3: Assessment and retrofitting of buildings, London: BSI; 2005.

[4] American Society of Civil Engineers (ASCE), ASCE 41-13, Seismic evaluation and retrofit of existing buildings, Reston, Virginia: 2014.

[5] N.M. Noh, L. Liberatore, F. Mollaioli, S. Tesfamariam, Modelling of masonry infilled RC frames subjected to cyclic loads: State of the art review and modelling with OpenSees. Engineering Structures, 150, 599-621, 2018.

[6] M.N. Fardis, T.B. Panagiotakos, Seismic design and response of bare and masonryinfilled reinforced concrete buildings part II: infilled structures. Journal of Earthquake Engineering, 1(03), 475-503, 1997.

[7] P.G. Asteris, S.T. Antoniou, D.S. Sophianopoulos, C.Z. Chrysostomou, Mathematical macromodeling of infilled frames: state of the art. J Struct Eng, 137(12), 1508-1517, 2011.

[8] G. Al-Achaar, Evaluating strength and stiffness of unreinforced masonry infill structures, Construction Engineering Research Laboratories, Report No. ERDC/CERL TR02-01, USA, 2002.

[9] A. S. Elnashai, L. Di Sarno, Fundamentals of Earthquake Engineering, Wiley and Sons, UK, 2008.

[10] S. Mazzoni, F. McKenna, M.H. Scott, G.L. Fenves, OpenSees command language manual, Pacific Earthquake Engineering Research (PEER) Centre, 264, 2006.

[11] British Standards Institution, BS EN 1998-1:2004, Eurocode 8. Design of structures for earthquake resistance - Part 1: General rules, seismic actions and rules for buildings, London: BSI; 2004.

[12] P. Fajfar, A nonlinear analysis method for performance-based seismic design. Earthquake spectra, 16(3), 573-92, 2000.

[13] L.F. Ibarra, R.A. Medina, H. Krawinkler, Hysteretic models that incorporate strength and stiffness deterioration, Earthquake engineering \& structural dynamics, 34(12), 1489-511, 2005.

[14] D.G. Lignos, H. Krawinkler, Deterioration modeling of steel components in support of collapse prediction of steel moment frames under earthquake loading, Journal of Structural Engineering, 137(11), 1291-302, 2010.

[15] C.W. Roeder, S.P. Schneider, J.E. Carpenter, Seismic behavior of moment-resisting steel frames: analytical study, Journal of Structural Engineering, 119(6), 1866-84, 1993.

[16] S.P. Schneider, C.W. Roeder, J.E. Carpenter, Seismic behavior of moment-resisting steel frames: Experimental study, Journal of Structural Engineering, 119(6), 1885-902, 1993. 
[17] T.L. Karavasilis, N. Bazeos, D.E. Beskos, Maximum displacement profiles for the performance based seismic design of plane steel moment resisting frames, Engineering Structures, 28(1), 9-22, 2006.

[18] SEAOC: Recommended lateral force requirements and commentary, 7th ed. 1999. 